\title{
JACQUES RANCIÈRE E A POLÍTICA DOS DIREITOS DOS ANIMAIS: A ESTÉTICA DA SUBJETIVIDADE JURÍDICA E A POLITIZAÇÃO DO SOCIAL
}

\author{
JACQUES RANCIÈRE AND THE POLITICS OF ANIMAL RIGHTS: THE \\ AESTHETIC OF LEGAL SUBJECTIVITY AND THE POLITIZATION OF \\ THE SOCIAL
}

\author{
Leonardo Monteiro Crespo de Almeida \\ Universidade Federal de Pernambuco - UFPE - (Recife, Pernambuco, Brasil) \\ Recebimento: 13 mar. 2019 \\ Aceitação: 21 maio 2019
}

\begin{abstract}
Como citar este artigo / How to cite this article (informe a data atual de acesso / inform the current date of access):
ALMEIDA, Leonardo Monteiro Crespo de. Jacques Rancière e a política dos direitos dos animais: a estética da subjetividade jurídica e a politização do social. Revista da Faculdade de Direito UFPR, Curitiba, PR, Brasil, v. 64, n. 2, p. 161-182, maio/ago. 2019. ISSN 2236-7284. Disponível em: https://revistas.ufpr.br/direito/article/view/65413. Acesso em: 31 ago. 2019. DOI: http://dx.doi.org/10.5380/rfdufpr.v64i2.65413.
\end{abstract}

\section{RESUMO}

O objetivo deste artigo reside em trazer para o âmbito da filosofia política de Jacques Rancière as dificuldades associadas com a animalidade no direito, normalmente concebidas por meio das discussões referentes aos direitos dos animais. Em vez de se deter nas implicações especificamente jurídicas desses direitos, da extensão que possuem ou mesmo de sua fundamentação, o artigo, ao recorrer a uma leitura muito particular da filosofia de Rancière, pretende apontar as condições que permitem ou obstruem a representatividade dos animais no campo jurídico. Para tanto, a pesquisa desenvolvida situa a maneira como os sujeitos jurídicos são construídos por meio da formulação de demandas em meio a um espaço social que não lhes reconhecem como vozes a serem ouvidas, ou seja, contestam as narrativas que impedem o reconhecimento institucional de suas vozes. Certas narrativas consensualmente estabelecidas dificultam, senão impedem, que os animais apareçam perante o direito como entes cujas vidas possuem valor e consideração. Uma das questões apontadas é que, apesar da existência e da produção cada vez mais ampla de normas jurídicas comprometidas com a proteção dos animais, estas podem estar vinculadas a imperativos econômicos, excluindo determinadas espécies do seu âmbito de proteção e incidência. $O$ artigo, por fim, salienta a importância de se manter em aberto questionamentos referentes a novas formas de juridicidade que levem em consideração, para além do cálculo de benefícios/custos e dos pressupostos antropocêntricos, o sofrimento e a condição precária dos entes não humanos.

\section{PALAVRAS-CHAVE}

Rancière. Estética. Direito dos animais. Política.

\begin{abstract}
This research main objective is to approach some specific problems of animality within legal studies through Jacques Rancière's political philosophy. It intends to point out conditions that allows or blocks the animal's representation in the legal field. The construction of the legal subject is conceived,
\end{abstract}


in this research, as a product of the formulation of political demands, especially when those individuals have no institutional visibility. There are certain patterns of institutional and political narratives that pose considerable difficulties to the legal representation and protection of animal's integrity, some of them dictated by powerful economic interests. In a nutshell, the article highlights the relevance of opening up theoretical investigations concerned with new modes of legal forms that would take into account the suffering and the precarious condition of non-human entities, above anthropocentric presuppositions and economical reasoning of costs and benefits.

\section{KEYWORDS}

Rancière. Aesthetic. Animal’s rights. Politics.

\section{INTRODUÇÃO}

As diversas prerrogativas jurídicas atribuídas aos indivíduos dependem preliminarmente das condições institucionais que permitem as suas implementações. Inexistindo essas condições, o que resta são promessas simbólicas dissociadas das circunstâncias materiais e sociais que cercam esses indivíduos, ou seja, que pouco contribuem para defender seus interesses ou preservar suas formas de vida. A teorização sobre o sujeito de direito abrange a estipulação dos entes que podem demandar e perseguir os seus interesses nos espaços jurídicos institucionais.

A ausência de subjetividade jurídica vem acompanhada por uma dimensão de invisibilidade na qual as narrativas e as formas usuais de exposição das demandas dos indivíduos não podem ser apreendidas pelo aparato institucional o qual se encontram vinculados. Imigrantes ilegais, por exemplo, inserem-se nesse cenário: a ilegalidade de sua condição impede que as suas demandas possam ser politicamente articuladas e juridicamente protegidas, mesmo quando os imigrantes se convertem em peças fundamentais para o desenvolvimento econômico e social do território no qual se encontram. O que está em questão não são os direitos e garantias sociais genericamente partilhados por todos, mas a maneira como alguém ou algo se torna duplamente visível, tanto no campo da política quanto no espaço institucional do jurídico.

A questão da visibilidade ou invisibilidade associa-se à maneira pela qual os animais são percebidos e representados nos sistemas jurídicos positivos. De início, as formas variadas com as quais os seres humanos estabelecem relações com animais fazem com que estes assumam diferentes configurações no horizonte mais amplo dos ordenamentos jurídicos positivos. Animais domésticos, normalmente objeto de diversas relações afetivas e familiares, tendem a dispor de um maior grau de proteção jurídica ante os que participam de rodeios. Nos segmentos referentes às pesquisas biomédicas e ou naqueles em que os animais são concebidos como matérias primas, a proteção é radicalmente minimizada ou inexistente. 
Um dos pontos significativos da filosofia política de Jacques Rancière reside na maneira como ele entrelaça dois domínios que, a rigor, não estão evidentemente associados: a política e a estética. Por estética é preciso compreender não especificamente uma teoria da arte ou do belo, mas as condições pelas quais os entes adquirem visibilidade no espaço político, visibilidade que, por sua vez, desdobra-se na possibilidade de ser visto e ouvido.

É a partir da articulação de uma demanda por igualdade, reivindicadora das condições pelas quais os indivíduos podem se fazer ver e ouvir nos espaços políticos estabelecidos, que a atividade política poderá reconfigurar os espaços que permitem a enunciação de certas necessidades e a obstrução contínua de outras tantas. A representação política, então, está diretamente vinculada à maneira pela qual os entes aparecem e podem ter as suas demandas assimiladas nos espaços políticos institucionalizados.

As várias demandas daqueles que militam em prol dos direitos dos animais, para além do pleito por mais leis e decisões judiciais que venham a proteger melhor a integridade deles, também terminam por trazer implicações significativas para a teorização do sujeito de direito e das potencialidades que vão integrar a configuração desse conceito. O que está em questão não são apenas os pressupostos antropocêntricos que fundamentam a subjetividade jurídica, mas também as condições pelas quais os animais podem ser passíveis de representação jurídica, o que não necessariamente precisa ser articulado por meio das modalidades usuais da personalidade jurídica.

O objetivo deste artigo consiste em investigar o potencial da filosofia política de Jacques Rancière para uma problematização referente aos limites e aos potenciais do conceito de sujeito de direito, para que se possa ponderar formas de outros mecanismos de subjetivação jurídica que sirvam para ancorar, mesmo que teoricamente, as diversas demandas suscitadas pelos proponentes dos direitos dos animais.

Para tanto, o artigo desenvolve uma leitura bastante particular da obra do filósofo francês em ao menos dois pontos: primeiro, ele insere no âmbito da dimensão estética da política um questionamento referente a sujeitos políticos que não são humanos; segundo, ainda no âmbito dessa discussão, o artigo acentua uma dimensão ética já presente nos trabalhos de Rancière, a saber, a ausência de reconhecimento dos grupos subjugados, como forma de colocar em questão o sofrimento e a condição precária, frágil, dos animais como aspectos significativos para se pensar o vínculo entre animalidade e juridicidade. Essa injunção ética, ao mesmo tempo que promove o reconhecimento das diversas circunstâncias precárias nas quais se encontram várias espécies de animais, também permite confrontar os limites das atuais formas de juridicidade e a maneira como enquadram e valorizam as experiências das formas de vida não humanas. 
Em termos metodológicos, o presente trabalho adota uma revisão de literatura que tem como principal eixo a filosofia política de Rancière, especialmente as suas noções de partilha do sensível e a distinção entre política/polícia. Recorre-se a certos textos de Jacques Derrida, Judith Butler e Drucilla Cornell com o propósito de pensar uma concepção de alteridade que escape do cálculo e da operacionalidade subjacente à aplicação do direito, e também às várias maneiras de limitar ou flexibilizar garantias estabelecidas. Semelhante ponto é importante principalmente porque ressalta que corpos, humanos e não humanos, podem ser destituídos de garantias e proteções jurídicas estabelecidas pelo próprio poder estatal.

\section{ESTÉTICA E POLÍTICA: COMUNIDADE E PARTILHA DO SENSÍVEL}

A filosofia de Jacques Rancière se desenvolverá como uma reflexão crítica e radical em torno dos modos de se fazer política prevalecentes no panorama francês da década de sessenta e setenta. Tendo como ponto de partida a sua crítica significativa ao estruturalismo marxista de Louis Althusser em La leçon d'Althusser, o filósofo investiga novos sentidos para a ideia de emancipação e de luta política em meio a um panorama de expansão das democracias liberais e consolidação do capitalismo. Em meio à crise do socialismo soviético e dos tradicionais partidos comunistas, a reflexão política do autor é conduzida pela preocupação em se teorizar novas formas de subjetividades políticas que não se deixem assimilar nem a um sujeito histórico que traria consigo as necessidades e as demandas da humanidade, nem uma inserção irrestrita nas democracias liberais.

O autor se insere em um contexto teórico no qual o pós-estruturalismo francês, representado por Gilles Deleuze, Michel Foucault, Jacques Derrida, entre outros, tornava-se mais forte ao mesmo tempo que crescia uma certa desconfiança, quando não aversão teórica, ao marxismo. Autores como Cornelius Castoriadis e Ernesto Laclau, por exemplo, mantiveram o comprometimento político de uma transformação do social da filosofia marxista ao mesmo tempo que redefiniram parcial ou completamente várias das suas principais premissas teóricas e estratégicas. É neste panorama que Jacques Rancière se encontra inserido.

A radicalidade do pensamento político em Rancière contempla ao menos dois eixos de investigação: a formação das subjetividades políticas e o resgate de um sentido originário, portanto mais profundo, de democracia. Em função da problemática desta pesquisa, apenas o primeiro eixo será enfatizado. A constituição de novas formas de subjetividade é desenvolvida pelo autor por meio de um entrelaçamento fundamental entre a política e a estética. Para que esse vínculo possa ser explorado com mais propriedade, é importante esclarecer como o autor concebe os dois termos, uma 
vez que, em sua obra, eles adquirem sentidos específicos e um tanto quanto distanciados daqueles encontrados no senso comum e mesmo em outras discussões teóricas.

Na filosofia política de Rancière, a estética é uma noção que alinha uma série de diferentes temáticas que vão sendo inseridas no desdobramento de suas obras, a exemplo da política. Em sua obra, política e estética formam uma relação de difícil dissociação e é por meio dela que o filósofo francês desenvolve uma noção central para esta pesquisa e também para a organização da reflexão política do próprio autor: trata-se da partilha do sensível. Rancière a concebe da seguinte forma:

\begin{abstract}
Eu chamo de partilha do sensível o sistema de fatos autoevidentes da percepção sensorial que simultaneamente revelam a existência de alguma coisa em comum e as delimitações que definem as respectivas partes e posições neles. A partilha do sensível, portanto, estabelece ao mesmo tempo algo em comum que é compartilhado e exclusivo (RANCIÈRE, 2000, p. 12, tradução nossa) $)^{1}$.
\end{abstract}

Diversas são as formas de distribuição que permitem aos indivíduos tomarem parte nas questões coletivas, como a que dispõe sobre quais deles podem ocupar posições na estrutura governamental e os que lhe são submissos. No entanto, antes mesmo da inserção dessa forma de contagem que opera uma demarcação no espaço do social, uma outra maneira de demarcação já se encontra estabelecida: a distinção entre aqueles que podem ser cidadãos e os que se encontram às margens da comunidade.

Recorrendo às formas de segmentação social presentes na democracia ateniense, mesmo que a um escravo seja possível a compreensão das ordens e dos enunciados emitidos por seu dono, ele permanecerá como parte não contada mesmo que, para Aristóteles, o próprio de um ente político é a sua fala. Numa concepção platônica, por sua vez, os artesãos estão impedidos de tomarem parte nos assuntos da polis uma vez que, envolvidos pelo trabalho cotidiano, já não dispõem de tempo para se dedicarem àqueles assuntos. Em ambos os casos - escravos e artesãos - a participação é inviabilizada não pelo que fazem ou deixam de fazer, mas em virtude da posição que ocupam no espaço social. Embora integrem economicamente a estrutura social, já que produzem e fazem circular bens e serviços, eles não são contados como parte para fins de deliberação e tomada de decisões que politicamente afetam o coletivo em geral.

Não ser parte reflete não só a inacessibilidade aos espaços institucionais, como algo ainda mais originário e decisivo: a exclusão mesma de se tomar parte no que é comum a todos. O vínculo entre estética e política, no contexto da partilha do sensível, não se refere a uma estetização da política

\footnotetext{
${ }^{1}$ No original: “J’appele partage du sensible ce système d'évidences sensibles qui donne à voir en même temps l'existence d'un commun et les découpages qui y définissent les places et les parts respectives. Un partage du sensible fixe donc en même temps un commun partáge et des parts exclusives.”
} 
ou de uma politização da arte, mas a um sistema de formas a priori que determina o que pode se apresentar à experiência sensível, delimitando o que pode ser visto e compreendido (RANCIÈRE, 2000, p. 12 et seq.). Para além de qualquer definição mais abrangente, a política é também uma modalidade de experiência. Se a partilha do sensível fornece as condições pelas quais alguém pode ter voz e se pronunciar sobre a comunidade, é preciso considerar também a possibilidade de uma reconfiguração das delimitações que caracterizam uma determinada partilha, ou seja, da possibilidade de que os sem-parte possam ser contados (RANCIÈRE, 1995, p. 26 et seq.).

Um aspecto relevante para esta temática e para o desenvolvimento da reflexão política de Rancière reside na distinção que faz entre a polícia e a política. É nela que se encontra não só um entendimento específico do propósito da política e mesmo da significação da ação política, como também uma compreensão mais abrangente e igualmente pontual da polícia. A polícia compreende parte de um regime estético no qual determinados entes aparecem como atores políticos, efetivos ou em potencial, e outros estão a priori excluídos desse domínio (RANCIÈRE, 1995, p. 51 et seq., 2010, p. 36 et seq.). Ela estabelece e mantem a ficção de que todas as partes se encontram incluídas na totalidade da comunidade, sendo contadas do mesmo modo. Rancière assim caracteriza a polícia em sua obra, 'O Desentendimento':

A distribuição dos lugares e dos papéis que definem a polícia e o regime emergem igualmente da espontaneidade das relações sociais quanto das rígidas funções estatais. A polícia é, essencialmente, o direito, geralmente implícito, que define a parte de um partido ou a sua falta. Mas que isso possa ser definido, você deve antes definir a configuração do perceptível em que um ou outro se encontra inserido (RANCIÈRE, 1995, p. 52, tradução nossa)².

Em termos mais concretos, o princípio da legalidade formal, ao dispor que todos são iguais perante a lei, encena uma situação na qual todos aqueles que dispõem de personalidade jurídica, ou seja, que são simbolicamente reconhecidos como indivíduos, podem demandar perante o Estado por meio das prerrogativas jurídicas que lhe foram concedidas. Na base desse dispositivo jurídico não se faz apenas presente uma noção de igualdade inscrita no imaginário social característico do direito moderno e dos seus mecanismos de integração social, como também a suposição de que a igualdade se adquire por meio de sua atribuição por alguma entidade, como o próprio Estado moderno ou outra autoridade equivalente. É essa a configuração que Rancière questiona.

O primeiro ponto é que a igualdade não é simplesmente atribuída por uma autoridade a um conjunto de indivíduos que lhe são submissos, sendo, antes, o pressuposto implícito das demandas

\footnotetext{
${ }^{2}$ No original: "La distribution des places et des fonctions qui définit un ordre policier relève autant de la spontanéité supposée des relations sociales que de la rigidité des fonctions étatiques. La police est, en son essence, la loi, généralement implicite, qui définit la part ou l’absence de part des parties. Mais pour définir cela, il fault d'abord définir la configuration du sensible dans lequel les unes et les autres s’inscrivent.”
} 
políticas. A igualdade é a noção pela qual uma determinada hierarquia ou sistema de valores, que serve de sustentáculo para uma configuração específica do social, será confrontada por meio da insurgência de elementos que, sendo desvalorizados ou ignorados, exigem tanto reconhecimento quanto transformações que proporcionem a permanência desse reconhecimento.

As demandas pela igualdade também trazem para o primeiro plano a falta constitutiva (wrong) que fraciona a comunidade entre os que possuem o direito de serem contados como aqueles que dispõem da fala, e os que serão relegados às margens do espaço político. A reconfiguração dessas relações somente pode vir a ocorrer por meio de uma força que permita a colisão dos "mundos" cindidos pela falta originária:

A política existe porque aqueles que não possuem nenhum direito de serem contados como seres falantes fazem eles mesmos algum relato, estabelecendo uma comunidade por meio do fato de serem vítimas de um erro comum que nada mais é do que essa confrontação mesma, a contradição de dois mundos em um só: um mundo no qual eles são e um mundo no qual eles não são, um mundo em que existe algo “entre" os que não os contam como seres falantes e um mundo em que nada existe (RANCIÈRE, 1995, p. 49-50, tradução nossa) ${ }^{3}$.

A exposição da falta proporciona o espaço no qual as formas de contagem ancoradas nos valores compartilhados podem ser confrontadas por meio da demanda por igualdade. Mas quem confronta? A resposta de Rancière é a seguinte: os que confrontam são aquelas partes que, não sendo contadas, são também sem-parte. É recorrendo à estrutura social e à dinâmica política da democracia ateniense que o filósofo francês vai sublinhar a maneira como a participação e a postulação de demandas emergem da transformação do demos, aqueles que não são parte, como sujeito político coletivo (RANCIÈRE, 1995, p. 53 et seq., 2004).

Nesta configuração política, a tensão entre os que são contados, e por isso tomam parte, e os que não o são, será estabelecida em termos de logos e phône. O primeiro termo se refere ao discurso inteligível, logicamente estruturado e marcado pela inteligibilidade; o segundo se refere aos sons dos animais, ininteligíveis e irracionais. Os que tomavam parte nos assuntos da polis partilhavam do logos, enquanto as formas de expressão e demandas do demos eram concebidas em termos de phône.

Um ponto de grande relevância na formulação de Rancière é que não adiantaria recorrer a qualquer procedimento deliberativo que viesse a permitir a assimilação dessas demandas: a fala e a visibilidade do demos já se encontram comprometidas e deslocadas desde o princípio. A precariedade

\footnotetext{
${ }^{3}$ No original: “Il y a de la politique parce que ceux qui n’ont pas droit à être comptés comme êtres parlants s’y font compter et instituent une communauté par le fait de mettre en commun le tort qui n'est rian d'autre que l'affrontement même, la contradiction de deux mondes logés en un seul: le monde où ils sont et celui où ils ne sont pas, le monde où il y a quelque chose "entre" eux et ceux qui ne les connaissent point comme êtres parlants et comptables et le monde où il n’y a rien.”
} 
dessa alocação é ancorada em uma série de narrativas e assertivas sobre a coexistência na comunidade às quais a polícia recorre para manter uma disposição determinada de corpos e vozes.

O filósofo francês pontua que o logos, compreendido como discurso, reside na base da lógica da política, mas assim o faz tornando manifesto (aisthêsis) o regime de distribuição e alocação de posições que permite dissociar, do barulho, os sons inteligíveis (RANCIÈRE, 1995, p. 48 et seq., p. 71 et seq.). Por essa razão os desentendimentos políticos, em suas raízes, não se restringem jamais ao esforço de clarificar e de tornar mais inteligível certo entendimento ou perspectiva; antes, terminam por confrontar as condições pré-existentes que estruturam o próprio intercâmbio de ideias. Rancière observa:

Cabe simplesmente apontar que a racionalidade política do argumento jamais pode ser uma simples clarificação acerca do que falar significa. Submeter proferimentos às condições de sua validade é colocar em disputa a maneira pela qual cada partido participa do logos. A situação de uma argumentação política deve sempre ser ganha na distribuição pré-existente e constantemente atualizada da linguagem dos problemas e da linguagem dos comandos (RANCIÈRE, 1995, p. 73-74, tradução nossa) ${ }^{4}$.

Investigar esse direcionamento significa trazer à tona a maneira pela qual as disputas políticas emergem dos enquadramentos, distinções e formas específicas de construção da comunidade e do seu significado. Disso não se segue que as relações de poder por si só obstruem e tolhem qualquer significação às formas institucionalizadas de deliberação política, mas, antes, que essas práticas se desenvolvem em contextos mais amplos e multifacetados, que estabelecem os critérios pelos quais as posições podem ser vencidas, os argumentos podem ser validados, e quais questões são passíveis de deliberação.

As diversas formas de enquadramento permitem não só a delimitação das vozes e corpos que podem participar, como a maneira de enforcar e expor as questões coletivas. Alguns exemplos: os assuntos políticos devem ficar a cargo daqueles que possuem as condições culturais e intelectuais para tanto; a população não dispõe de tempo ou preparo para lidar com questões técnicas, com os problemas coletivos de natureza jurídico-política. A maneira pela qual os corpos, as vozes e os assuntos aparecem reflete a dinâmica específica da política, especialmente no tocante à construção e à emergência de novas formas de subjetividade. Desenvolvendo mais os elementos que compõem o conceito de polícia, Joseph Tanke observa:

\footnotetext{
${ }^{4}$ No original: “C'est seulement dire que cette rationalité politique de l'argumentation ne peut jamais être la simple explicitation de ce que parler veut dire. Soumettre les énoncés aux conditions de leur validité, c’est mettre en litige le mode sur lequel le logos est participé par chacune des parties. Une situation d'argumentation politique doit toujours se gagner su le partage préexistant et constamment reproduit d'une langue des problèmes et d'une langue des ordres."
} 
As divisões da polícia distribuem corpos e vozes, definem o que é visto e o que não é visto, e desenham fronteiras, como as que existem entre o público e o privado. É a polícia, por exemplo, que nos diz que as disputas salariais são questões privadas entre trabalhadores e empregadores. Pode-se então dizer que a "polícia" se refere a uma série de assertivas que estruturam a vida em comum com o objetivo de se evitar a política (TANKE, 2011, p. 46, tradução nossa $)^{5}$.

Evitar a política envolve um duplo movimento: o primeiro se refere à estipulação de uma narrativa para a organização simbólica do social, enquanto o segundo se refere à manutenção das formas de consenso por meio do qual a narrativa única se mantém e se perpetua. Em vez de sublinhar o caráter contingente e artificial de sua emergência, as narrativas e distinções transformam o arranjo entre as diferentes partes do social em algo natural e/ou necessário, conforme Rancière destaca em Platão e Aristóteles.

Para fins do desenvolvimento teórico desta pesquisa, o relevante a ser destacado reside na maneira pela qual os sujeitos políticos são construídos a posteriori e em função de uma demanda específica contrária a uma que os impede de tomar parte em uma cena estabelecida (RANCIÈRE, 2010, p. 29 et seq.). A dinâmica da política não está em tomar parte nos espaços de decisão coletivos acerca dos assuntos que são comuns a todos: a política está no processo de reconfiguração da partilha do sensível, o que envolve a contestação das formas de contagem estabelecidas em narrativas consensuais (RANCIÈRE, 2010, p. 27 et seq.).

A política, então, mostra-se nesse raro e específico momento de insurgência em que, por meio da demanda pela igualdade, o que existe é a insurgência por meio da qual um segmento do social luta contra a sua exclusão dos espaços políticos usuais. A dimensão estética da ação socialmente transformadora reside em inserir, dentro de uma conjuntura que se estabelece como narrativa unitária, outras formas de imaginário do social que podem vir a existir.

Muito embora essa linha de argumentação não aborde diretamente a constituição da subjetividade jurídica, ela realça as bases pelas quais essa subjetividade pode ser estabelecida e operacionalizada. Quando essa temática toma como referência os seres humanos, uma maneira de conceber a relação entre estética e subjetividade jurídica é situando as diversas estratégias que mantêm os sem-parte à deriva, incapacitados de adentrar nos centros de decisão, com isso mantendose invisíveis em termos jurídico-políticos. Se os sem-parte não são contados, falta-lhes a dimensão simbólica por meio da qual alguém pode dispor de prerrogativas e garantias jurídicas protegidas pelo Estado. Uma possibilidade seria a atribuição de direitos e garantias que, por sua vez, ao menos na

\footnotetext{
${ }^{5}$ No original: "Police divisions distribute bodies and voices, define what is seen and unseen, and draw boundaries, such as those that exist between the public and the private. It is the police, for example, that tells us that salary disputes are private matters between workers and employers. It can thus be said that "police" refers to the series of assumptions that structure life in common with the aim of avoiding politics”.
} 
prática, não encontraram concretização na vivência prática e coletiva dos cidadãos.

Deslocar esse foco para uma análise de possíveis formas de subjetividade que poderiam ser atribuídas aos animais, por outro lado, é algo que demanda um esforço teórico maior e que situa a abordagem de Rancière para além dos limites das suas incursões temáticas habituais. Antes, porém, é pertinente considerar os obstáculos e os limites que circundam a teorização sobre a animalidade no âmbito jurídico.

\section{UMA OUTRA FORMA DE EXISTIR NO DIREITO: A CONSTRUÇÃO JURÍDICA DO ANIMAL}

O primeiro desafio da teorização da subjetividade jurídica do animal é o da naturalização do sujeito de direito, ou seja, a essência da subjetividade jurídica reside na natureza do ser humano e somente ele, nesta acepção, pode assumir essa configuração. Pensar dessa maneira implica desconsiderar as múltiplas formas pelas quais as categorias jurídicas organizam e reorganizam a realidade na qual pretendem intervir e resolver problemas. É esquecer a contingência de sua criação, ignorando a importância da sua dimensão tecnológica, ou seja, a maneira como cada categoria é orientada para a resolução dos problemas dos juristas, em vez de se pretender delimitar um aspecto imutável e perene da realidade. Sendo assim, perante o problema da atribuição de responsabilidade aos entes que são compostos por coletivos de indivíduos, como empresas e autarquias, a doutrina responde por meio da categoria de pessoa jurídica, ainda que esses entes coletivos sejam, de certo modo, abstrações.

Edward Mussawir observa que, no desenvolvimento histórico da invenção de novos direitos, o que se tem são linhas de fuga que saem de uma concepção universalizante de ser humano para vários polos minoritários, como mulheres, refugiados, trabalhadores, etc. (MUSSAWIR, 2011, p. 57 et seq.). Reside neste ponto um certo paralelismo entre a criação de novos direitos e a construção de novos modos de ser e estar no - e a partir do - jurídico, como se pode antever já no próprio conceito de partilha do sensível.

Um aspecto importante na filosofia política de Rancière é que a composição das subjetividades sucede, ao invés de preceder, a formulação de demandas que põe em questão as diferentes formas de contagem que politicamente dispõe os diversos entes no espaço social. Sendo assim, a concepção universalizante da qual fala Mussawir pode ser concebida, no horizonte da filosofia política de Rancière, como pressuposto estético que vai delimitar os entes capazes de adquirir subjetividade jurídica, de que modo ela pode ser exercida e quais as condições para o seu 
reconhecimento institucional.

A atribuição de direitos traz consigo as possibilidades de exercícios e prerrogativas dos direitos atribuídos. Direitos sem condições de exercício refletem tão somente narrativas que beneficiam um pequeno segmento da totalidade do social. As formas de contestação dessas narrativas adquirem estratégias diversas conforme os objetivos e as finalidades daqueles que as confrontam.

A preocupação protetiva que envolve a atuação dos proponentes dos direitos dos animais tende a ser pensada a partir da lógica liberal dos direitos individuais, tal como se desenvolveram no período moderno. Mas pensar animalidade não significa necessariamente compreender a aquisição e exercício dos direitos pelos animais em termos que se desenvolvem a partir das categorias já consolidadas de personalidade jurídica. A insistência nesse caminho não só desconsidera o potencial de criatividade e plasticidade que existe na criação das categorias jurídicas, como outros sentidos que podem ser dados ao jurídico e ao exercício dos direitos.

Cary Wolfe destaca, recorrendo às reflexões de Jacques Derrida acerca da temática, que um pouco de cautela é importante para que o corte humano/animal não se torne refém das vigentes estruturas conceituais do direito (WOLFE, 2013, p. 16 et seq.). O que se pretende não é apenas inovar as leis, torná-las mais sensíveis ao sofrimento e à precariedade da condição dos animais - o que não deixa de ser muito válido -, mas também interrogar as próprias bases conceituais do direito que sustentam a existência desse panorama.

Existe um certo paralelismo entre essa abordagem e aquela sustentada por Rancière quando este repensa o conceito de política e o sentido da transformação nesse panorama. A política poderia ser pensada em termos de articulação dos interesses entre aqueles que já são parte, mas isso somente contribuiria para reiterar uma determinada configuração da partilha do sensível: o sujeito que se constitui politicamente é uma parte que se subtrai a um arranjo que lhe é pré-existente, ou seja, a emergência dessa subjetividade implica sempre uma reconfiguração da partilha do sensível.

Esforços teóricos comprometidos com a elaboração de leis e propostas que transformem favoravelmente as condições dos animais podem acabar desconsiderando os pressupostos jurídicos e filosóficos que, antes de mais nada, permitem as circunstâncias que se busca transformar. Seria preciso estabelecer um meio termo entre trabalhar a partir do que se faz presente e uma abertura capaz de reconsiderar as bases conceituais do que hoje se encontra juridicamente estabelecido. Derrida tece a seguinte consideração acerca deste ponto:

Para este momento, nós devemos nos limitar a trabalhar as regras do Estado de direito tal como elas existem. Mas será eventualmente necessário reconsiderar a história deste direito e compreender que muito embora os animais não possam ser colocados em conceitos tais como 
cidadãos, consciência associada à fala, sujeito, etc., eles não estão deste modo totalmente destituídos de “direito". É o próprio conceito de direito que deverá ser "repensado" (DERRIDA; ROUDINESCO, 2014, p. 74, tradução nossa) ${ }^{6}$.

Reconsiderar o direito, neste horizonte, envolve também considerar a maneira pela qual os animais são assimilados a uma série de outras concepções que os tornam completamente disponíveis aos imperativos técnicos dos seres humanos (BRAIDOTTI, 2013, p. 7 et seq.). Uma situação ilustrativa reside em tratá-los como commodities ou utilizá-los em experimentos. Em ambas as circunstâncias, Cary Wolfe assinala a dificuldade que se tem em relação a certas leis, como a Animal Welfare Act (AWA) e a Humane Methods of Livestock Slaughter Act (HSA) (WOLFE, 2013, p. 12 et seq.). Em ambos os casos, a conceitualização dos animais como coisas os coloca de fora do âmbito de proteção das leis.

No que se refere ao Animal Welfare Act, por exemplo, Wolfe observa que camundongos, pássaros e ratos, que respondem por 95\% dos animais utilizados em experimentos científicos, encontram-se fora do âmbito de proteção normativa presente nessas leis. Situação semelhante pode também ser transposta ao segmento das commodities. A Humane Methods of Livestock Slaughter Act, orientada para a humanização dos processos de abatimento, inclui bois e cavalos, mas deixa de lado frangos e galinhas, espécies que compõem a maior parte dos abatimentos presentes nos Estados Unidos (WOLFE, 2013, p. 12 et seq.).

Ao mesmo tempo que novas leis são aprovadas para proteger a integridade dos animais, seja pela imposição de sanções jurídicas ou pela humanização dos procedimentos de abate, elas são limitadas aos interesses econômicos circundantes. A disponibilidade integral dos animais como commodities ou objeto de experimento, situando-os efetivamente como corpos disponíveis, traz para o primeiro plano a necessidade de uma interrogação mais profunda acerca da natureza não apenas dos direitos, como também da composição de novas formas de personalidades jurídicas. O que Derrida aponta é uma abertura para aquilo que, neste momento, integra o campo do impensável como um problema - a busca por novas modalidades de direitos para os animais - cuja solução hoje permanece de difícil apreensão.

Um dos gestos dessa abertura, embora por certo não seja o único, reside na reiteração da pluralidade dos animais em detrimento de se afirmar uma totalidade uniforme, o animal. Significa postular não somente uma diversidade incomensurável, mas uma alteridade que se desfaz quando o

\footnotetext{
${ }^{6}$ No original: "For the moment, we ought to limit ourselves to working out the rules of law [droit] such as they exist. But it will eventually be necessary to reconsider the history of this law and to understand that although animals cannot be placed under concepts like citizen, consciousness linked with speech, subject, etc., they are not for all that without a 'right'. It's the very concept of right that will have to be 'rethought'”.
} 
animal é pensado e constituído tendo como referência as necessidades e satisfações dos seres humanos, um cruzamento entre gestão da vida e capitalismo (BRAIDOTTI, 2013, p. 42 et seq.). Sendo essas as referências, é razoável esperar que, perante as normas jurídicas, eles apareçam primeiramente como entes disponíveis, cuja relevância de sua existência está diretamente vinculada à valoração humana.

A reconfiguração da partilha do sensível, especialmente no tocante às formas institucionais de representação jurídica e defesas de interesses, depende, por sua vez, de uma redefinição dos elementos constitutivos da subjetividade jurídica, especialmente daqueles que a vinculam a traços específicos dos seres humanos, a exemplo da linguagem e consciência. Mais uma vez, se a política representa o momento de emergência das partes que não são contadas como partes, isso significa que todos os pressupostos estéticos que impedem esse movimento precisam ser confrontados. No âmbito jurídico, no que se refere à animalidade, é preciso reconsiderar o antropocentrismo que formata e limita os diversos modos de expressão da subjetividade jurídica.

Em síntese, ressaltar a construção jurídica dos animais significa enfatizar as diversas formas pelas quais ele aparece para o direito e o tipo de tratamento - ou ausência dele - que vai se desdobrar a partir desse ponto. Embora associado às fontes formais do direito, como as leis ou a jurisprudência, a subjetividade jurídica pressupõe e estabelece as condições e restrições, limites e possibilidades, de qualquer ente no espaço institucional do direito. É neste ponto que, para a linha de argumentação desta pesquisa, reside também a dimensão estética tal como Rancière a concebe.

A caracterização dos animais como commodities, entes que podem ser livremente dispostos em diferentes testes laboratoriais, ou que, devido à inserção afetiva no convívio familiar, demandam também proteção e consideração, reflete as diversas maneiras com que os entes se tornam visíveis diante do ordenamento jurídico positivo. Nesse contexto, insistir em uma defesa em prol de mais direitos e/ou torná-los mais efetivos significaria pressupor não apenas que os animais já estariam envolvidos por alguma modalidade de personalidade jurídica, como também necessariamente restringir a proteção deles a um sistema de garantias e prerrogativas, tal como o modelo dos direitos no mundo romano (WOLFE, 2013, p. 17 et seq.).

Um dos ganhos teóricos do conceito de partilha do sensível para esta problemática reside em uma dupla consideração teórica: ao mesmo tempo que as condições de visibilidade que amparam a participação institucional são discutidas em primeiro plano, o conceito de partilha do sensível viabiliza também o confrontamento dessas mesmas condições. Em outras palavras, permite o enquadramento de questões, como a referente aos animais, em disposições distintas daquelas que se fazem presentes nas atuais estruturas jurídicas que, aliás, não precisam ser tomadas nem como ponto 
de partida necessário, menos ainda como referência central.

Em ao menos dois de seus livros, Precarious Life e Frames of War, Judith Butler levanta questões importantes acerca da maneira como os corpos são enquadrados, organizados e dispostos nas diferentes narrativas que integram a dinâmica das instituições e também do próprio imaginário social. À polarização que dividia o mundo entre os que eram a favor dos Estados Unidos e aqueles que eram contra, Butler indaga pelas diversas formas de valorização da vida, em que algumas podem ser objeto de luto enquanto outras se mostram dispensáveis.

A disposição dos corpos pode ser suficiente para contornar a proteção presente nos direitos constitucionais, e o contexto pós-11 de setembro, nos Estados Unidos, forneceu exemplos bastante ilustrativos dessas práticas. O departamento de justiça e o departamento de defesa norte-americanos, juntos, instruíram os tribunais militares a não considerarem o direito de alguns detentos, tenham sido eles detidos no país ou na prisão de Guantánamo (BUTLER, 2004, p. 50 et seq.). Entre esses direitos estão aquele de se comunicar com um advogado, obtendo auxílio jurídico, e também o próprio direito a um julgamento, ambos fundamentais e constitucionalmente assegurados.

A inobservância do direito a um julgamento traz à tona, a princípio, possibilidades que dispõem contra elementos centrais da ideia do Rule of Law, a exemplo da detenção indefinida, mas revela as ambiguidades que integram os fundamentos do modelo de direitos a que Derrida evitou recorrer quando confrontou a temática dos direitos dos animais: a ausência de uma injunção ética torna o modelo de direitos devedor de uma avaliação prévia e circunstancial do valor e da significação dos corpos que lhe são dispostos.

Se, na situação analisada, os imperativos de segurança nacional permitem a suspensão de garantias e direitos estabelecidos, ao mesmo tempo fazem surgir um exercício de soberania que atua às margens do jurídico, possibilitando uma modulação circunstancial dos poderes administrativos para se determinar quem pode ser julgado e os que já não possuem mais essas prerrogativas (BUTLER, 2004, p. 51 et seq.). A elaboração e a aplicação da AWA e HSA, ainda que firmemente inscritas no domínio do jurídico, revelam formas de flexibilização similares ao panorama aludido por Butler, na medida em que, em função dos imperativos econômicos e culturais, segmentos de animais são postos para fora do âmbito normativo de leis que, a princípio, existiriam para garantir a sua integridade e proteção.

Uma das ideias centrais propostas por Butler em Precarious Life, e que é levada adiante também em Frames of War, reside em que as determinadas vidas, para quem possam ser objeto do luto e da perda, precisam antes ser apreendidas como dotadas de vida (BUTLER, 2009, p. 1 et seq.), algo também pontuado por Derrida (DERRIDA, 2007, p. 34 et seq.). Essa abordagem está em sintonia 
com a interpretação que esta pesquisa propõe de uma parte específica da filosofia política de Rancière, referentes aos seus conceitos de partilha do sensível e da distinção polícia/política: a maneira como a vida é apreendida a partir de um esquema que, sendo inteiramente político, vai preexistir às formas e aos espaços institucionais de deliberação política e proteção jurídica.

A intuição de Butler referente às detenções indefinidas no pós-onze de setembro põe em questão a maneira pela qual as garantias e proteções inscritas no direito positivo podem ser "torcidas” ou deslocadas para que certos fins sejam alcançados, levando a uma suspeita do Rule of Law. Esta é ainda mais significativa quando pensada no horizonte da problemática jurídica do animal, uma vez que é a significação mesma da sua existência e sofrimento que vai permanecer indefinida.

\title{
3 CONSIDERANDO O SOFRIMENTO E A PRECARIEDADE: A CONVERGÊNCIA ENTRE POLÍTICA, ESTÉTICA E ÉTICA
}

Se a dimensão estética proposta por Rancière, no cenário da política, traz à tona um certo processo de formação da subjetividade política, poderia essa mesma política abrir espaço para outras formas de inserção? Uma resposta positiva, ainda que restrita, seria a seguinte: é desejável construir mecanismos inclusivos, embora estes permaneçam no âmbito da administração funcional dos corpos e dos limites da comunidade, não se confundindo com a política.

No que concerne aos animais, como foi observado, a criação de leis e mecanismos institucionais, que venham a promover o seu bem-estar, vistos na HSA e na AWA, terminam por colidir com imperativos não jurídicos que obstruem - ou em muito diminuem - a sua materialização. Uma injunção ética se centraria, antes mesmo de tecer qualquer consideração jurídica, no sofrimento e na vulnerabilidade que os seres humanos compartilham com os animais. Cora Diamond assim desenvolve essa linha de reflexão:

\begin{abstract}
A consciência de que cada um de nós possui um corpo vivo, estando "vivo para o mundo", traz consigo a exposição a um sentido corporal de vulnerabilidade à morte, uma vulnerabilidade animalesca, a vulnerabilidade que nós partilhamos com eles. Esta vulnerabilidade é capaz de nos deixar em pânico. Ser capaz de reconhecer tudo isso, e inclusive compartilhar, machuca; mas reconhecê-la como algo que partilhamos com outros animais, considerando o que fazemos com eles, é capaz não somente de nos deixar em pânico, como também de nos isolar... Existe alguma dificuldade em ver o porquê de preferirmos não retornar ao debate moral, em que a vida e a morte dos animais aparece como fatos que tratamos como relevantes desta ou daquela forma, e não como presenças que desestabilizam a nossa razão? (DIAMOND, 2008, p. 78 et seq., tradução nossa) ${ }^{7}$.
\end{abstract}

\footnotetext{
${ }^{7}$ No original: "The awareness we each have of being a living body, being "alive to the world", carries with it exposure to the bodily sense of vulnerability to death, sheer animal vulnerability, the vulnerability we share with them. This vulnerability is capable of panicking us. To be able to acknowledge it at all, let alone as shared, is wounding; but
} 
A tomada de consciência referente ao que os seres humanos partilham com os animais em termos de vida, sofrimento e morte abre espaço para uma experiência ética na qual o que se encontra em jogo são as formas de percepções mesmas que moldam e organizam a vivência dos animais nas sociedades humanas, incluindo as diversas tipologias jurídicas presentes nos ordenamentos jurídicos positivos. Por isso, é no desenvolvendo da reflexão ética que Cora Diamond constitui um paralelismo que não só pode conectar as considerações de Rancière e Butler sobre a disposição política dos corpos, como também traz à tona a maneira como a submissão presente nas relações entre os próprios seres humanos vão ser transpostas para a maneira como eles vão conceitualizar o animal e o seu sofrimento: o horror da conceitualização de animais como não sendo nada exceto coisas depende de um horror comparável à inquietação humana e à falta de compaixão no exercício do poder referente a outros seres humanos (WOLFE, 2013, p. 17).

O que é decisivo para essa discussão, no horizonte de uma reflexão jurídica, reside em que a desconsideração do momento ético torna politicamente disponíveis os corpos que, a princípio, encontram amparo e proteção nas normas jurídicas positivas. Muito embora trate-se de corpos e situações específicas, a tortura dos suspeitos de afiliação com organizações terroristas ocorre tanto às margens da legislação estabelecida ou por meio de um recorte técnico, conforme mencionado por Butler, que estabelece determinados cenários como exceções; logo, não acolhidas pela abrangência inicial das disposições normativas.

Seguindo as considerações de Wolfe, algo muito semelhante se sucede a certas formas de proteção jurídica dos animais, que podem ser moldadas ou contornadas por meio da sobreposição dos interesses econômicos às garantias jurídicas. Se algumas espécies de animais são enquadradas como objetos que se encontram livremente à disposição dos seres humanos, antes de qualquer consideração jurídica sobre a questão, o que se faz presente é uma desconsideração de qualquer forma de sofrimento ou semelhança entre aquele animal e o humano.

Quando Rancière analisa a interposição das demandas pelo demos, a distinção entre logos e phône é indispensável para que a noção de igualdade traga ao primeiro plano a maneira como as formas de contagem inviabilizam mesmo a participação popular. O abismo entre logos e phône não reflete um desencontro de linguagens específicas, e sim os limites de reconhecimento do Outro como um ente que traz consigo possibilidades alternativas de organização do social. Para além da

acknowledging it as shared with other animals, in the presence of what we do to them, is capable not only of panicking one but also of isolating one... Is there any difficulty in seeing why we should not prefer to return to moral debate, in which the livingness and death of animals enter as facts that we treat as relevant in this or that way, not as presences that may unseat our reason?” 
linguagem, essa é uma problemática centrada no Outro e no seu enquadramento.

Se, seguindo as considerações do filósofo francês, a política aponta uma dinâmica de reconfiguração estética da comunidade por meio de uma demanda pela igualdade promovida por aqueles que não tomam parte, a injunção ética também pode representar uma linha que desestabiliza as narrativas consensuais dominantes por meio da consideração de relações que, a rigor, não se inserem nos enquadramentos e limites estabelecidos pelo que dita a própria narrativa. A consideração do sofrimento animal, por exemplo, pode abrir caminhos de investigação não somente sobre as formas de relação do ser humano com os outros entes, como também buscar o desenvolvimento de novas categorias técnicas que permitam outros mecanismos de proteção jurídica que não aqueles baseados nos direitos subjetivos.

Agora, no entendimento desta pesquisa, a maneira pela qual a injunção ética acerca do sofrimento dos animais será considerada depende também do questionamento das narrativas que impedem a visibilidade dos animais como algo mais do que propriedade, coisa, mercadoria. Isso significa interrogar diretamente noções que são culturalmente muito caras e estabelecidas, mas que ofuscam, senão excluem, certos animais como passíveis de consideração e acolhimento. Não se trata da projeção de características e elementos humanos, senão do reconhecimento de uma alteridade intransponível diante de um Outro incomensurável, sendo nessa relação mesma que o humano vai se desdobrar.

Nesse processo também um outro componente, ainda mais significativo para se pensar a animalidade no direito, será interrogado: a lógica da calculabilidade que reflete a disposição dos corpos animais por meio dos imperativos da norma jurídica. Se, por um lado, a atribuição dos direitos subjetivos aos animais esbarra nos seus pressupostos antropológicos que revestem tanto a teoria do direito quanto as construções filosóficas e aquelas que lhe são associadas (CALARCO, 1998, p. 104), por outro lado a disponibilidade do cálculo representa uma obstrução à concretização de qualquer possibilidade que permita ao animal existir como animal, não mais como objeto, coisa ou commodity, perante um ordenamento jurídico positivo particular. O direito está, desde o seu princípio, circunscrito ao cálculo e ao determinado (DERRIDA, 2007, p. 30 et seq.).

A consideração do sofrimento introduz o incalculável dentro de uma ordem marcada pelo cálculo: uma vez que o sofrimento, em uma perspectiva que reconhece a alteridade incomensurável do Outro que traz consigo a sua diferença, excede a quantificação, também rejeita o estabelecimento de equivalências e da própria relação custo/benefício que sempre integra o cálculo. O sofrimento sem o reconhecimento dessa alteridade, por sua vez, pode ser prontamente remetido à ordem do cálculo: o sacrifício, embora doloroso, de certos animais pode ser justificado pelos benefícios que trará para 
os seres humanos, a exemplo de novas curas para as enfermidades existentes e outros elementos que possam vir a agregar à sua qualidade de vida (DERRIDA, 2007, p. 34 et seq.). É um raciocínio que em muito se assemelha com a ausência de proteção de certas espécies em função das implicações econômicas que poderiam vir a proporcionar.

Para que a alteridade possa ser situada desta maneira, é necessário que a mesma seja pensada dissociada de qualquer sistema de referências que apreenda o Outro. Em sua obra O animal que logo sou, Derrida expõe o sentimento de vergonha que surgiu ao literalmente se deparar nu diante do seu gato de estimação (DERRIDA, 2002, p. 15 et seq.). A vergonha impõe uma dupla reação que coloca em xeque não só o sentido da identidade, mas sua relação com o outro: a primeira relação dispõe a sensação de nudez como humana ao mesmo tempo que a ausência dessa sensação o remete ao âmbito do próprio animal (DERRIDA, 2002, p. 16 et seq.).

Em síntese, por um lado, ao não perceber a sua própria nudez diante do outro, Derrida é exatamente como o gato, mas, por outro lado, na medida em que o gato desperta o filósofo para a sua própria nudez, o gato é também humano. Não existe uma resolução final para esses dois eixos que se desdobram em meio à sensação sorrateira da vergonha relatada pelo filósofo argelino. No entanto, tem-se uma abertura para uma investigação filosófica referente às dificuldades e aos fracassos dos filósofos de pensar esse encontro simultaneamente banal e singular. O que se tem é a constatação da instabilidade referente à distinção entre humano e animal (CALARCO, 1998, p. 105 et seq.). Acerca da alteridade do animal, James Siegel observa o seguinte:

Este gato é, de fato, “totalmente outro”. É concebido deste modo em vez de ser transformado em algo a ser admirado ou tornado figura - do mal, da beleza, da sabedoria - tal qual o outro selvagem cuja alteridade é ameaçadora. Não se trata de uma figura, reitera Derrida. É apenas um outro, um de “todos os outros” que é “totalmente outro” (SIEGEL, 2011, p. 236-237, tradução nossa) ${ }^{8}$.

Então, se a alteridade do animal é remetida a um sistema de referências pré-existente - seja na forma dos direitos subjetivos, seja por meio de categorias jurídicas prontamente operacionais, como a personalidade, ou mesmo outras estruturas de significação -, o que acaba sendo obstruída é a abertura que proporcionaria ao jurídico uma investigação persistente sobre o sentido, em primeiro lugar, do próprio jurídico e, posteriormente, das múltiplas possibilidades de se apreender a animalidade no domínio do jurídico. Possibilidades estas que não se deixam deter pela ausência de uma linguagem comum e pela irracionalidade, mas que, reconhecendo esses entraves, deixam em

\footnotetext{
${ }^{8}$ No original: “This cat is, indeed, 'totally other'. It is taken as such rather than being transformed into something to be wondered at or made into a figure - of evil, of beauty, of wisdom - in the way of the savage other whose otherness is threatening. It is not a figure, Derrida says. It is simply an other, one out of 'all others' who is 'totally other'”.
} 
aberto uma meditação em torno do sofrimento, da dor e da partilha que não seja enclausurada em uma estrutura de significação estabelecida (CORNELL, 1992, p. 56 et seq.).

Conforme Jean-Philippe Deranty, o núcleo da reflexão política proposta por Rancière reside na negação do reconhecimento daqueles que são subjugados (DERANTY, 2003, p. 137 et seq.). Se a política é, desde o seu princípio, estética, isso implica a abertura de direcionamentos que visam a confrontar a percepção da realidade social, materializada nas narrativas consensuais sobre o comum, propondo desta maneira novas formas de percepção. Se a emergência de novas correntes artísticas confronta as maneiras usuais de percepção da realidade social, assim também se sucede com a política (RANCIÈRE, 2000, p. 13 et seq.).

No que se refere à relação entre animalidade e direito, o principal entrave teórico para uma política dos direitos dos animais reside em superar o modelo de direitos subjetivos. Para além dos seus pressupostos antropocêntricos, esse modelo é envolvido pela lógica do cálculo, de modo a abrir espaço a uma seletividade e disposição de certos animais, ignorando não somente o seu sofrimento, como também a significação de sua existência. Assim como Rancière não propõe elementos normativos com os quais se podem avaliar os rumos das transformações políticas, também permanece em suspenso quais seriam os mecanismos jurídicos que simultaneamente permitiriam a consideração dos animais ao mesmo tempo que transpõem a dimensão de operacionalidade que acompanha o exercício dos direitos subjetivos.

Uma solução parcial para essa questão é menos importante do que manter presente uma abertura que coloca em questão o sentido do jurídico e a maneira como os mais distintos entes vão aparecer diante dele. A mencionada abertura permitiria uma investigação nessa direção ao trazer para o primeiro plano as diversas formas de sofrimento e subjugação que, até então, são desconsideradas pelas instituições jurídicas. É neste ponto que ocorre um cruzamento entre política, estética e ética: pensar uma forma de reconciliação e reconhecimento que, em vez de eliminar a heterogeneidade do Outro animal em uma estrutura normativa pré-existente, permita que ela aflore para que novas possibilidades do jurídico possam ser contempladas (CORNELL, 1992, p. 16 et seq.).

\section{CONSIDERAÇÕES FINAIS}

O propósito central desse artigo foi o de transpor um ponto central da reflexão de Rancière sobre política e estética, a saber, o conceito de partilha do sensível, para a inserção jurídica dos animais, seja a título de representação propriamente dita, seja a título de sua proteção. A relevância dos conceitos de Rancière para este tema reside na maneira pela qual ele desvincula a política dos 
mecanismos institucionais que caracterizam a política em seu sentido usual, ou seja, ele está indagando pelas condições que permitem a alguém - ou algo - adentrar no âmbito desses mecanismos. Em síntese, a política compreendida também como a formação de sujeitos políticos coletivos.

Um dos traços recorrentes na relação entre animalidade e direito é a ausência de uma compreensão de subjetividade, referente aos animais, que venha a extrapolar as concepções assentadas sobre o que é ser sujeito de direito, uma vez que elas se desenvolvem e se circunscrevem aos seres humanos e suas particularidades (a fala, a consciência, a racionalidade, etc.). O que se tem é um cenário no qual os conceitos e categorias técnicas do direito esbarram com as limitações dos seus pressupostos teóricos: ao mesmo tempo que, gradualmente, cresce uma certa inquietação pela falta de proteção e disponibilidade dos animais no âmbito jurídico, faltam os elementos, também jurídicos, que permitiriam a superação desse cenário. Existem duas barreiras significativas neste ponto.

A primeira delas é a aceitação e difusão de narrativas, sejam elas econômicas, científicas ou de outra natureza, que atuam na disponibilização do animal, situando-o como algo que existe em função dos interesses humanos, ou seja, para atender às suas pretensões e necessidades. Essas narrativas constituem um regime de visibilidade que dificulta, e em alguns casos impede, outras formas de consideração da animalidade, inclusive no âmbito jurídico. Confrontar essas narrativas em prol das demandas sufocadas, implícitas, é um ato político com profundas ressonâncias éticas.

A segunda delas é que, uma vez que as categorias jurídicas referentes à personalidade e à representação em juízo estão fundadas em pressupostos antropológicos, conforme já mencionado, qualquer forma de visibilidade dos animais na esfera jurídica necessariamente será medida pelos interesses e perspectivas humanos. Por isso Derrida, ao questionar a transposição do modelo dos direitos subjetivos para a esfera dos animais, reitera a importância de se pensar formas de proteção jurídica dos animais ao mesmo tempo que enfatiza a importância de deixar em aberto as investigações referentes a novas configurações do jurídico.

Estabelecendo a problemática desta maneira, a filosofia política de Rancière se converte em um instrumental analítico capaz de suscitar um ponto relevante para além da formação dos sujeitos políticos e da desvinculação entre a dinâmica das instituições políticas concretas de uma comunidade e a própria participação política: as condições que antecedem - e possibilitam - a inserção de entes como sujeitos dotados de garantias e prerrogativas políticas. Se o filósofo francês compôs essa questão mediante o cenário inicial da política ateniense, nas demandas pela igualdade formuladas pelo demos diante daqueles que já se encontravam inseridos na polis grega, a transposição dessa 
reflexão para o âmbito jurídico dos direitos dos animais serve para abrir linhas de investigação produtivas, ao mesmo tempo que isola e esclarece certos aspectos da subjetividade jurídica.

Um desses aspectos reside na dimensão estética das categorias jurídicas e as diversas implicações políticas em que não só elas se apoiam como também produzem: trata-se da maneira pela qual o jurídico constrói tipologias e formas de enquadramento dos animais tendo como referência interesses e arranjos que lhe são exteriores, a exemplo do mercado e do desenvolvimento científico.

Uma vez que certos animais são concebidos como entes inteiramente disponíveis, o que lhes resta é a submissão a uma lógica do cálculo que os deixa submetidos não às garantias jurídicas disponíveis, mas à relação entre custos e benefícios. Leis e decisões judiciais podem ser contornadas - ou moldadas - para que sejam mais restritivas e seletivas, permitindo que as garantais e proteções sejam enfraquecidas ou tornadas indisponíveis. Em síntese, não podem encontrar amparo na norma jurídica porque, a rigor, não são reconhecidos como seus destinatários.

Por isso a injunção ética da qual fala Derrida pode levar, neste ponto, a reflexões teóricas significativas, ao romper com a lógica do cálculo cega às condições e ao sofrimento dos animais. O ético se associa ao político na medida em que propõe uma reconfiguração estética da comunidade: novos sujeitos e as relações estabelecidas entre eles, que, outrora ignoradas, passam a ser contadas. Essa abertura permite que novas vozes, corpos e experiências adentrem na composição de narrativas coletivas, amplas e compartilhadas, que projetam novas possibilidades de existir para aquela comunidade. A política já não aparece aqui como uma forma de gerir os interesses, por vezes concorrentes, entre os membros já incluídos da comunidade; antes, ela busca abrir espaço para futuros impensados.

\section{REFERÊNCIAS}

BRAIDOTTI, Rosi. The Posthuman. Cambridge: Polity Press, 2013.

BUTLER, Judith. Frames of War: When is Life Grievable? London: Verso, 2009.

BUTLER, Judith. Precarious Life: The Powers of Mourning and Violence. London: Verso, 2004.

CALARCO, Matthew. Zoographies: The Question of the Animal from Heidegger to Derrida. New York: Columbia University Press, 1998.

CORNELL, Drucilla. The Philosophy of the Limit. London: Routledge, 1992.

DERANTY, Jean-Philippe. Jacques Rancière's Contribution to the Ethics of Recognition. Political Theory, v. 31, n. 1, 2003, pp. 136-156. 
DERRIDA, Jacques. Força de Lei: O “Fundamento Místico da Autoridade”. São Paulo: Martins Fontes, 2007.

DERRIDA, Jacques. O animal que logo sou. São Paulo: Editora UNESP, 2002.

DERRIDA, Jacques; ROUDINESCO, Elisabeth. For What Tomorrow: A Dialogue. Stanford, CA: Stanford University Press, 2004.

DIAMOND, Cora. The Difficulty of Reality and the Difficulty of Philosophy. In: CAVELL, Stanley; DIAMOND, Cora; MCDOWELL, John; HACKING, Ian; WOLFE, Cary. Philosophy and Animal Life. New York: Columbia University Press, 2008.

MUSSAWIR, Edward. Jurisdiction in Deleuze: The Expression and Representation of Law. London: Routledge, 2011.

RANCIÈRE, Jacques. Aux bords du politique. Paris: Folio, 2004.

RANCIÈRE, Jacques. Dissensus: On Politics and Aesthetics. London: Continuum Press, 2010.

RANCIÈRE, Jacques. La mésentente: Politique et philosophie. Paris: Editions Galiléé, 1995.

RANCIÈRE, Jacques. Le Partage du sensible: Esthétique et polique. Paris : La fabrique editions, 2000.

SIEGEL, James. “Tout Autre est Tout Autre”. In: BERGER, Anne Emmanuelle; SEGARRA, Marta. Demenageries: Thinking (of) Animals after Derrida. Amsterdam: Rodopi, 2011, pp. 213243.

TANKE, Joseph J. Jacques Rancière: An Introduction. London: Continuum Press, 2011.

WOLFE, Cary. Before the Law: Humans and Other Animals in a Biopolitical Frame. Chicago: The University of Chicago Press, 2013. Doutor e Mestre em Direito pela Faculdade de Direito do Recife (UFPE). Bacharel em Direito pela AESO. Bacharel em Filosofia pela UFPE. E-mail: leonardoalmeida326@gmail.com 